\title{
DISTRIBUSI VISCOUS, FRICTION DAN ELECTRIC DUMPING PADA REGENERATIF SHOCK ABSORBER (RSA) TIPE HYDRAULIC ELECTRO MECHANIC SHOCK ABSORBER (HEMSA)
}

\author{
Wanda Afnison ${ }^{1 *}$, Bahrul Amin ${ }^{1}$ \\ ${ }^{1}$ Jurusan Teknik Otomotif, Fakultas Teknik, Universitas Negeri Padang \\ *e-mail: udawanda10@gmail.com
}

\begin{abstract}
Abstrak- Besar koefisien viscous, friction dan electric dumping sangat berpengaruh terhadap karakteristik dan energy bangkitan yang dihasilkan shock absorber. Semakin besar nilai dumping koefisien maka secara langsung akan mengurangi energi input mekanisme harvesting energy. Pada penelitian ini akan di deskripsikan seberapa besar nilai dumping koefisien untuk 3 variabel (viscous, friction dan electric), sehingga kita dapat mengetahui karakteristik dari Regeneratif Shock Absorber. Data ini juga dijadikan acuan dalam melakukan pengembangan Regeneratif Shock Absorber kedepannya. Penelitian ini menggunakan metode experimen dengan memasang shock absorber pada alat uji suspensi (Suspension Test Rig). Pengujian dilakukan 3 tahap dimana masing-masing tahap dilalui akan diperoleh 3 nilai dumping koefisien (viscous, friction dan electric). Dari hasil pengujian diperoleh nilai viscous dumping sebesar 518 N.s/m (rebound) dan 694 N.s/m (Compression), friction dumping sebesar 113 N.s/m (rebound) dan 232 N.s/m (Compression), electic dumping sebesar 476 N.s/m (rebound) dan 390 N.s/m (Compression). Sektor Viscous dumping memiliki rerata dumping koefisien tertinggi sebesar 606 N.s/m dan terendah pada friction dumping sebesar 172.5 N.s/m. Besaran dumping koefisien masing-masing item dijadikan data acuan dalam pengembangan RSA ke depan.
\end{abstract}

Kata Kunci : Viscous dumping, Friction dumping,Electric dumping

\begin{abstract}
The number of viscous coefficient, friction and dumping electric are very influenced to the characteristics and regenerative energy which is made of shock absorber. The more dumping coefficient number will directly minimise the input mechanisms of harvesting energy. In this research will be described the number of dumping coefficient for 3 variables (viscous, friction, electric), so that we know the characteristics of regenerative shock absorber. This data can be used as the reference on development of regenerative shock absorber. This reserch used experimental method by putting the shock absorber on the suspension test rig. There are 3 steps of the test and there will be 3 dumpling coefficient for each (viscous, friction and electric). From the result of the test, it was obtained that the value of viscous dumping is $518 \mathrm{~N} . \mathrm{s} / \mathrm{m}$ and $694 \mathrm{N.s} / \mathrm{m}$ (Compression), friction dumping is $113 \mathrm{N.s} / \mathrm{m}$ (rebound) dan $232 \mathrm{N.s} / \mathrm{m}$ (Compression), electic dumping is $476 \mathrm{N.s} / \mathrm{m}$ (rebound) dan $390 \mathrm{N.s} / \mathrm{m}$ (Compression). Viscous dumping sector has the highest coeficient dumping which is $606 \mathrm{N.s} / \mathrm{m}$ and the lowest is on the friction dumping which is $172.5 \mathrm{~N} . \mathrm{s} / \mathrm{m}$. The number of each dumping coefficient can be used as reference data to develop RSA in the future.
\end{abstract}

Keywords : Viscous dumping, Friction dumping,Electric dumping

Copyright @ 2017 INVOTEK. All rights reserved

\section{PENDAhuluan}

Krisis energy fosil menjadi pemicu bermunculannya penelitian terkait harvesting energy dan energy terbarukan. Salah satu mekanisme harvesting energy yang sedang banyak digunakan di kendaraan adalah VEH (Vibration Energy Harvesting). Pada dasarnya cara kerja VEH adalah dengan memanfaatkan gerak relatif kendaraan terhadap jalan. Gerak relatif ini ditangkap dan dikonversi ke system VEH sehingga dapat menghasilkan energi listrik. Pada penelitian ini VEH diaplikasikan dalam RSA (Regeneratif Shock Absorber) yaitu shock absorber yang mampu menghasilkan energy listrik. Jadi disamping menhasilkan keamanan dan kenyamanan berkendara, shock absorber ini juga mampu menghasilkan energi listrik untuk dimanfaatkan bagi keperluan energy mobil. RSA (Regeneratif Shock Absorber) yang dibuat masih dalam bentuk prototype dan dalam masa 
pengembangan. Berikut rancangan dari RSA (Regeneratif Shock Absorber):

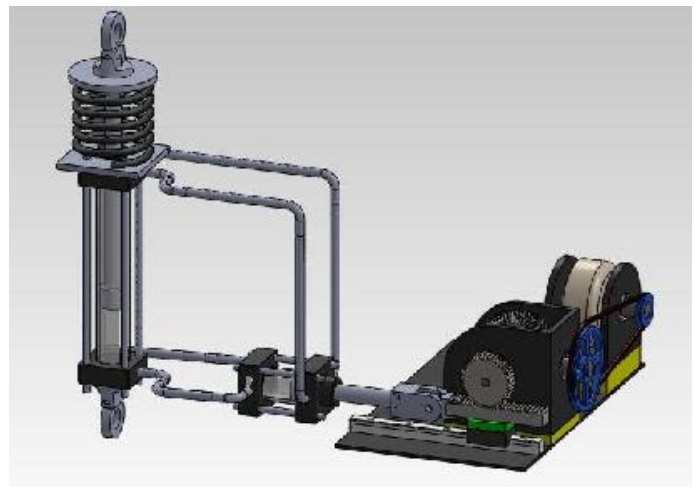

Gambar 1.1: Desain Prototype RSA tipe Hydraulic Electro Mechanic Shock Absorber (HEMSA)

Penelitian ini akan membahas RSA yang menggunakan silinder hidrolik dengan perbandingan diameter 30:40. Selang yang digunakan double port, 2 kompressi dan 2 rebound. Gerak translasi aktuator digunakan untuk menggerakkan silinder hidrolik 1. Gerakan silinder hidrolik 1 menjadi menjadi input bagi silinder hydrolik 2, gearbox dan generator. Output generator kemudian disalurkan ke lampu sebagai beban. Pada RSA (Regeneratif Shock Absorber) terdapat 3 jenis dumper yaitu viscous dumping yang dihasilkan sistem hydraulic, friction dumping yang dihasilkan oleh mekanisme roda gigi dan electric dumping yang dihasilkan oleh generator. Besaran nilai dumping yang dihasilkan sangat berpengaruh terhadap karakteristik dan energi bangkitan yang dihasilkan. Pada jurnal ini akan dideskripsikan besaran dumping yang dihasilkan dari masing-masing aspek.

\section{STUDI PUSTAKA}

\section{A. Getaran Harmonik}

Salah satu contoh gerak harmonik sederhana adalah gerakan pegas dalam posisi vertikal yang diujungnya diberi beban $m$ dimana gaya gesek dengan udara diabaikan. Ketika pegas tidak mendapatkan gaya maka benda $m$ berada di titik y $=0$, yang disebut sebagaititik kesetimbangan sistem. Ketika pegas diberikan gaya dengan ditarik maka pada pegas akan timbul gaya pemulih (restoring force) $F x$ yang besarnya berbanding lurus dengan simpangan $y$ dan berlawanan arah dengan arah gaya pada pegas. Jika dituliskan dalam bentuk matematis :
Persamaan di atas sebagai persamaan pegas dan merupakan hukum Hooke dimanak adalah konstanta pegas dan $y$ adalah simpangan. Tanda negatif menunjukkan bahwa gaya pemulih $F x$ mempunyai arah berlawanan dengan simpangan $y$. Ketika pegas di tarik ke bawah maka $y$ bernilai positif, tetapi arah $F x$ ke atas (berlawanan arah dengan simpangan $y$ ) sehingga gaya $F x$ selalu bekeja berlawanan arah dengan arah simpangan $y$. Konstanta pegas $k$ berkaitan dengan elastisitas sebuah pegas. Semakin besar konstanta pegas, semakin besar gaya yang diperlukan untuk menekan atau meregangkan pegas. Semakin kecil konstanta pegas, semakin kecil gaya yang diperlukan untuk meregangkan pegas.

Jika ditinjau dengan hukum kedua Newton :

$$
\begin{aligned}
& m \frac{d^{2} y}{s+2}+k y=0 \\
& \frac{d^{2} y}{d t^{2}}+\frac{k}{m} y=0
\end{aligned}
$$

Jika $k / m=\omega^{2}$ maka:

$$
\frac{d^{2} y}{d t^{2}}+\omega^{2} y=0
$$

Dalam bentuk lain menjadi:

$$
\begin{aligned}
& D^{2} y+\omega^{2} y=0 \\
& \left(D^{2}+\omega^{2}\right) y=0
\end{aligned}
$$

Solusi umum dari persamaan diferensial orde dua di atas adalah

$$
y=A \sin (\omega t+\varphi)
$$

Jika persamaan tersebut diturunkan terhadap waktu diperoleh persamaan kecepatan dari benda dan jika diturunkan lagi maka akan diperoleh persamaan percepatan dari benda.

$$
\begin{aligned}
& \frac{d y}{d t}=\omega A \cos (\omega t+\emptyset) \\
& \frac{d^{2} y}{d t}=-\omega A \sin (\omega t+\emptyset) \\
& \frac{d^{2} y}{d t}+\omega^{2} x=0
\end{aligned}
$$

Frekuensi $f$ dan perioda $T$ dari sistem pegas (Frieck, 1995) adalah :

$$
\begin{aligned}
& f=\frac{\omega}{2 \pi}=\frac{1}{2 \pi} \sqrt{\frac{k}{m}} \\
& T=\frac{2 \pi}{\omega}=2 \pi \sqrt{\frac{m}{k}}
\end{aligned}
$$

$$
F x=-k y
$$




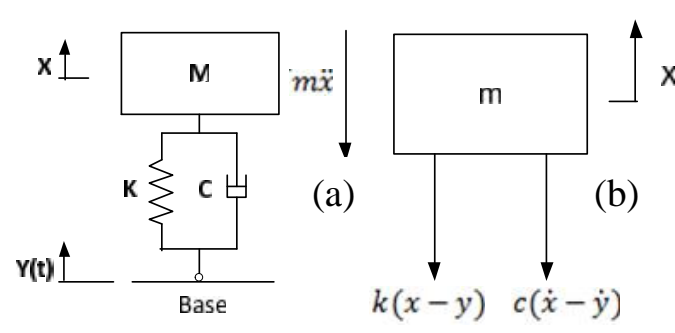

Gambar 2. 1 Motion Base

(a) Sistem fisik base excitation (b) Free body diagram untuk sistem base excitation

Eksitasi input y (t) menyatakan perpindahan dari base, dan $\mathrm{x}$ (t) menyatakan perpindahan massa dari posisi kesetimbangan statis pada waktu t. Maka perpanjangan dari pegas adalah $(x-y)$ dan kecepatan relatif antara kedua ujung damper adalah $(x-y)$. Dari free body diagram yang ditunjukkan pada gambar 2.7(b), didapatkan persamaan gerak:

$F=k(x-y)+c(\dot{x}-\dot{y})=-m \ddot{x}$

$F=m \omega^{2} X \sin (\omega t-\emptyset)=F_{t} \sin (\omega t-\emptyset)_{(}$

Dimana Ft merupakan nilai amplitudo tertinggi yang diberikan ke base, sehingga rasio gaya transmissibility nya (Rao, 2011) sebagai berikut :$$
\frac{F t}{K Y}=r^{2}\left[\frac{1+(2 \zeta r)^{2}}{\left(1-r^{2}\right)^{2}+(2 \zeta r)}\right]^{1 / 2}
$$

Berikut ini adalah grafik force transmissibility:

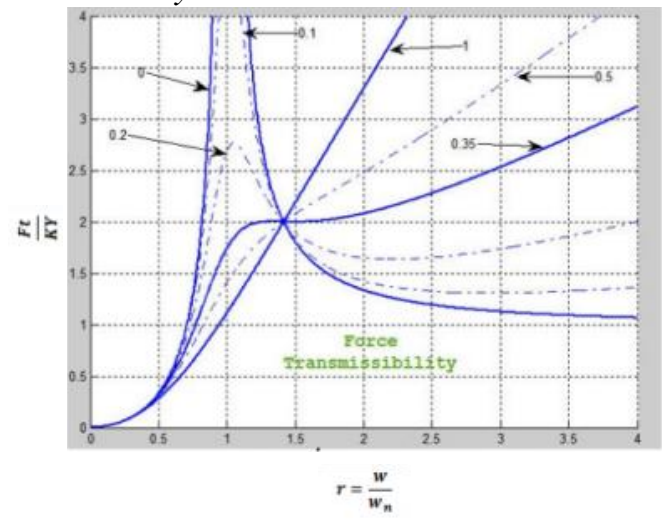

Gambar 2. 2 Grafik Force Transmisibility vs Frequency Ratio

\section{B. Konstanta Redaman}

Pada suatu sistem dengan satu derajat kebebasan terdapat tiga parameter, yaitu massa $(m)$, konstanta pegas $(k)$ dan konstanta redaman (c). Nilai konstanta Redaman sistem dapat dicari dengan menggunakan persamaan gerak berikut ini:

$$
F d=c \dot{\mathrm{x}}
$$

Keterangan :

$\mathrm{Fd}$ : Damping force $(\mathrm{N})$

$\dot{x} \quad$ :Kecepatan eksitasi $(\mathrm{m} / \mathrm{s})$

c : Konstanta redaman

\section{METODE}

\section{A. Diagram Alir Penelitian}

Proses pengujian HEMSA dapat dilihat pada flowchart berikut:

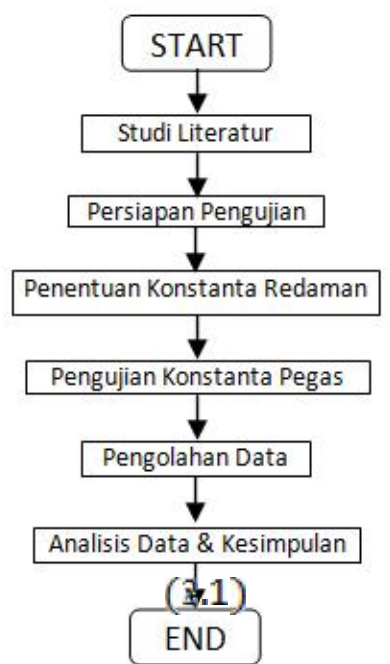

Gambar 3.1 Flowchart mekanisme pengujian HEMSA

\section{B. Penentuan Konstanta Redaman Hydraulic} Electro Mechanic Shock Absorber

Uji statis dengan metode pembebanan dilakukan untuk mengetahui nilai dari konstanta redaman HEMSA. Pada HEMSA ada beberapa nilai konstanta redaman yang dapat diperoleh: konstanta redaman hydrolik, elektrik, mekanik dan terakhir nilai konstanta redaman seluruh system HEMSA dengan pemasangan external load (lampu).

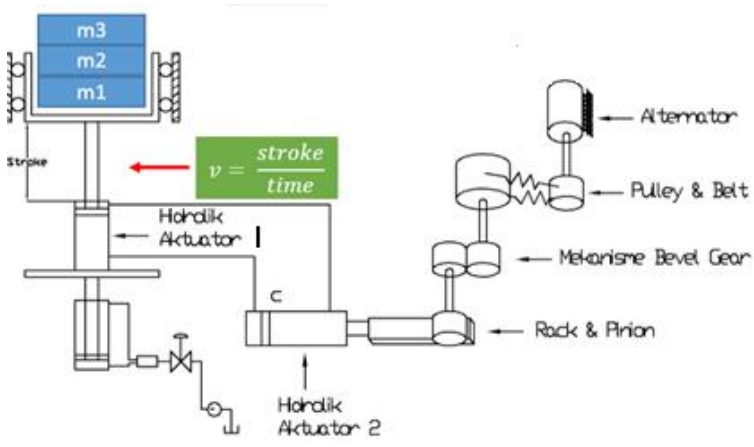

Gambar 3.2 Skema Uji Statis 
Proses pengujian dilakukan dengan memasang HEMSA pada suspension test rig seperti gambar diatas. Hydrolik actuator 1 diposisikan pada TMA (titik mati atas) dan catat jarak langkah (stroke) hydrolik actuator 1 sebelum mencapai TMB (titik mati bawah). Dengan melakukan variasi penambahan beban $\mathrm{m} 1, \mathrm{~m} 2$, m3 maka didapatkan kecepatan turun massa sprung. Pengujian ini dilakukan untuk mengetahui distribusi redaman masing-masing sistem pada HEMSA diantaranya redaman hidrolik, elektrik, mekanik. Besarnya nilai redaman dari sistem diperlukan sebagai acuan dalam melihat karakteristik HEMSA.

1. Mekanisme penentuan konstanta redaman viscous damping.

Nilai viscous damping diperoleh dengan memasangkan hydrolik actuator 1 dan 2 pada suspension test rig sesuai gambar dibawah. Untuk pengujian viscous damping hanya menggunakan dua buah hydrolik actuator sedangkan perangkat lain seperti mekanisme roda gigi dan generator dilepas sementara.

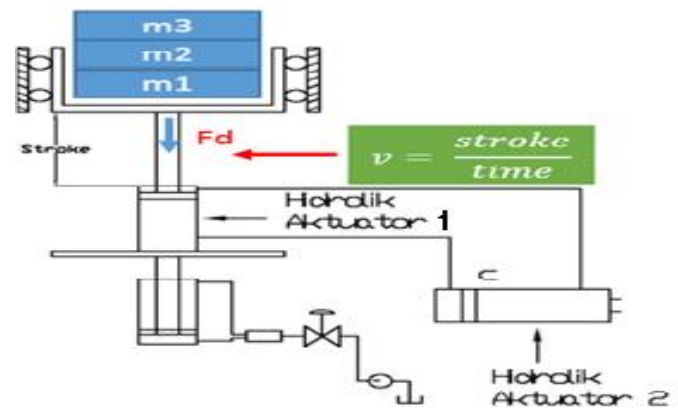

Gambar 3.1 Skema pengujian viscous damping.

Pada Flowchar tberikut dapat dilihat penentuan konstanta redaman viscous damping:

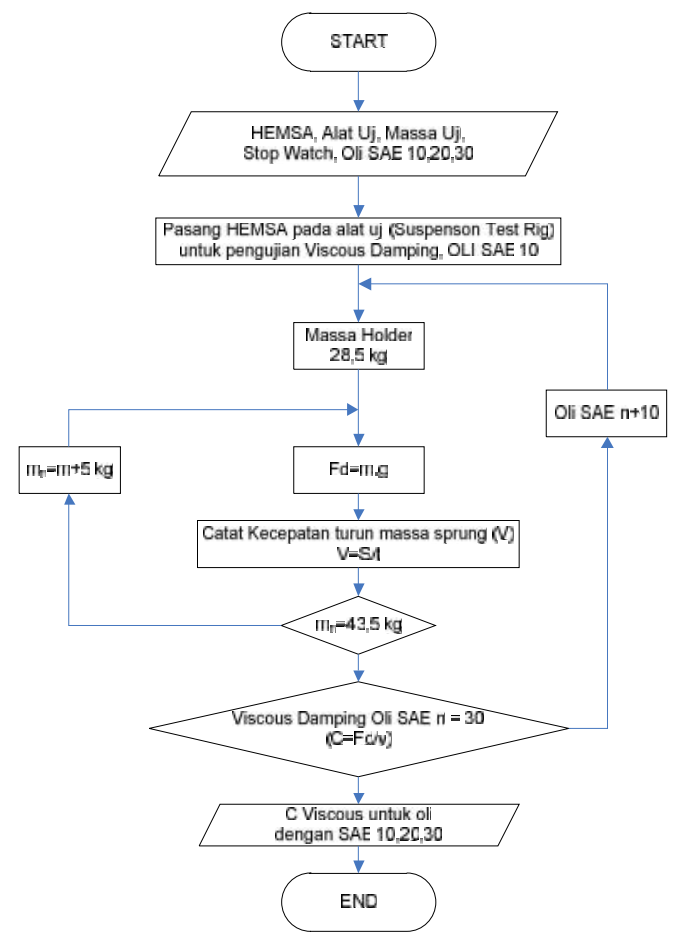

Gambar 3.2Flowchart penentuan konstanta redaman viscous damping.

2. Mekanisme penentuan konstanta redaman viscous + friction damping.

Untuk mendapatkan nilai dari friction damping terlebih dahulu maka harus dipasangkan mekanisme roda gigi yag terhubung dengan tabung hyrolik 2. Nilai friction damping $\mathrm{C}_{\text {friction }}=\mathrm{C}_{\text {viscous+friction }}-\mathrm{C}_{\text {viscous }}$.

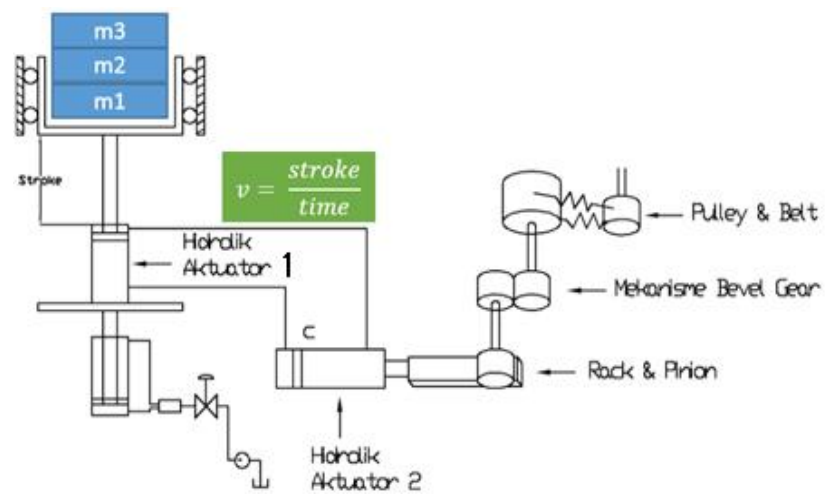

Gambar 3.3 Skema pengujian viscous + friction damping. 
Berikut flowchart penentuan konstanta redaman viscous + friction damping:

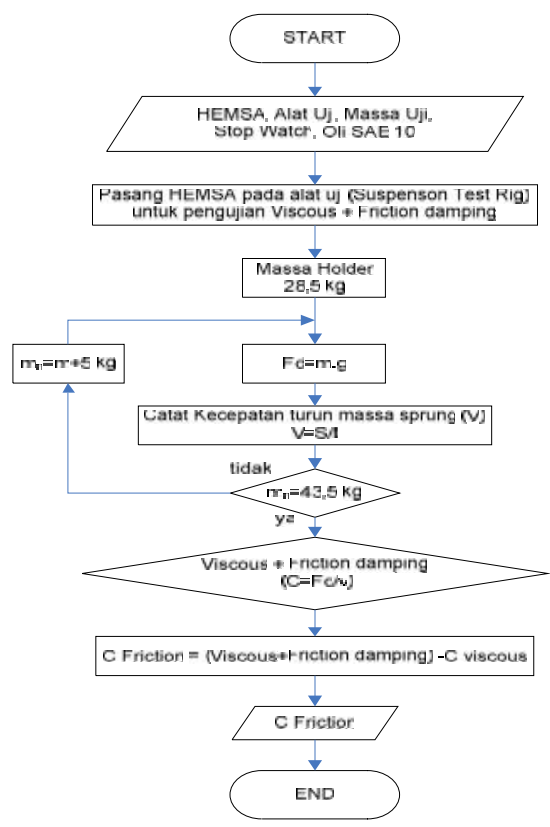

Gambar 3.4 Flowchart penentuan konstanta redaman viscous + friction damping.

\section{Mekanisme penentuan konstanta redaman} viscous + friction + electric dampingdengan pembebanan lampu.

Beban lampu yang digunakan adalah sebesar 30 watt. Nilai konstanta redaman dengan pembebanan lampu ini diperoleh dengan memasangkan lampu pada system yang sudah dirakit sebelumnya (hydraulic system, mechanical system dan electrical system). Pemasangan lebih detail dapat dilihat pada gambar berikut:

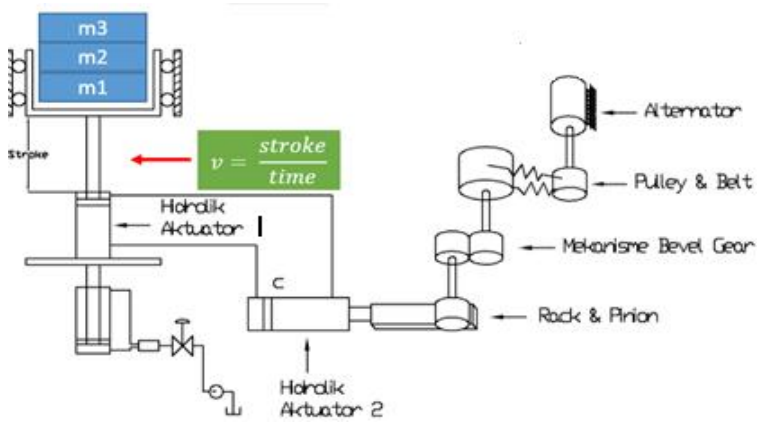

Gambar 3.5 Skema pengujian konstanta redaman viscous + friction + electric damping dengan pembebanan lampu

Berikut flowchart penentuan konstanta redaman viscous + friction + electric dampingdengan pembebanan lampu.

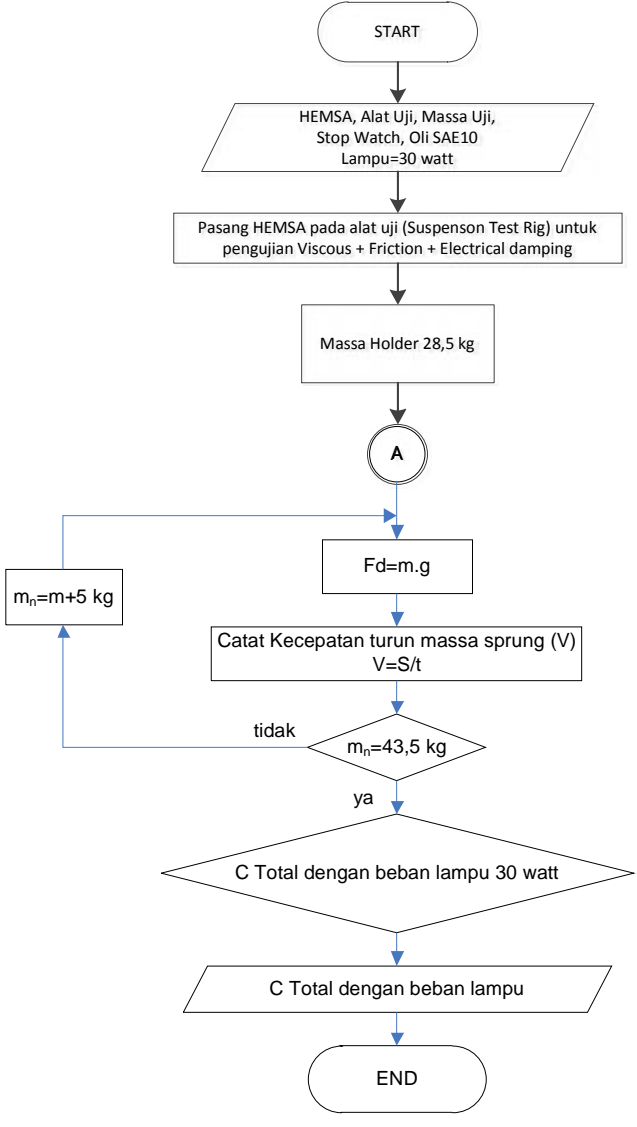

Gambar 3.6Flowchart penentuan konstanta redaman viscous + friction + electric damping dengan pembebanan lampu

\section{HASIL DAN PEMBAHASAN}

\subsection{Penentuan nilai viscous dumping}

Pengujian viscous damping dilakukan untuk mengetahui nilai konstanta redaman yang disebabkan silinder Hydraulic pada HEMSA. Selain berfungsi sebagai peredam, silinder hydraulic juga berfungsi sebagai transfer gaya eksitasi yang diberikan actuator untuk dilanjutkan ke mekanisme gearbox dan setelahnya diteruskan ke system electric (generator). Nilai konstanta redaman yang dihasilkan system hydraulic saat compression dan rebound diperoleh dengan persamaan $\mathrm{Fd}=$ C.v. Berikut adalah grafik hasil pengujian gaya redaman viscous damping yang dilakukan saat compression dan rebound: 


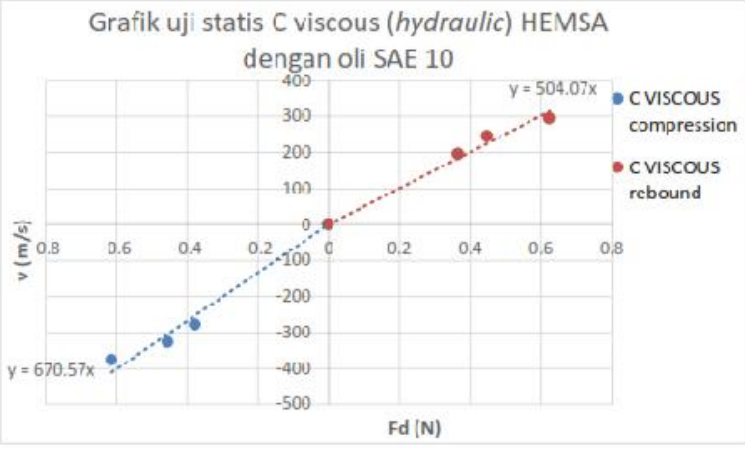

Gambar 3.9. Grafik uji redaman viscous dumping

Dari grafik diatas dapat kita lihat nilai konstanta redaman saat compression adalah 694 $\mathrm{Ns} / \mathrm{m}$ dan pada saat rebound nilai konstanta redaman adalah $518 \mathrm{Ns} / \mathrm{m}$. Pada kondisi ini diperoleh nilai rata-rata redaman pada system hydraulic (compression dan rebound) yaitu sebesar $606 \mathrm{Ns} / \mathrm{m}$.

\subsection{Penentuan Nilai Friction Dumping.}

Nilai friction damping diperoleh dengan melakukan pengujian dimana HEMSA sudah terpasang mekanisme gear box (tanpa pulley ke generator). Nilai redaman yang diperoleh kemudian dikurangi dengan nilai viscous damping yang sudah diperoleh sebelumnya Berikut data yang diperoleh dari proses pengujian friction damping (Compression):

\begin{tabular}{|c|c|c|c|c|c|c|c|c|}
\hline \multicolumn{9}{|c|}{ HI KONSIANIA IRIIIAMAN (VISCOUSH HICION) } \\
\hline $\begin{array}{c}\begin{array}{c}\text { Massa } \\
\text { (kg) }\end{array} \\
\text { (a) }\end{array}$ & $\begin{array}{l}\text { Massa } \\
+ \text { hoider } \\
\text { (NU) }\end{array}$ & $\begin{array}{l}\text { Berat } \\
\text { (N) }\end{array}$ & $\begin{array}{l}\text { WAKTU } \\
\text { (5) }\end{array}$ & $\begin{array}{c}\text { STROKE } \\
(\mathrm{m})\end{array}$ & $\underset{(m / s)}{V}$ & $\begin{array}{c}v \text { rata2 } \\
(\mathrm{m} / \mathrm{s})\end{array}$ & $\begin{array}{c}c \\
\text { (nss/m) }\end{array}$ & $\begin{array}{l}\text { Crata2 } \\
(\mathrm{Ns} / \mathrm{m})\end{array}$ \\
\hline 0 & 0 & 0 & 0 & 0 & 0 & 0 & 0 & 0 \\
\hline 0 & 28.45 & -279.095 & 1.02 & -0.32 & -0.3137 & -0.303 & 890 & 922 \\
\hline 0 & 28.45 & $-2 / 9.095$ & 1.1 & -0.32 & -0.2909 & & 959 & \\
\hline o & 38.45 & -279.095 & 1.05 & -0.32 & -0.3047 & & 916 & \\
\hline 5 & 33.45 & -328.145 & 0.97 & -0.32 & -0.3299 & -0.331 & 995 & 991 \\
\hline 3 & 33.42 & $-328.14 \mathrm{~s}$ & 0.95 & -0.32 & -0.3368 & & $9 / 4$ & \\
\hline 5 & 33.45 & -328.143 & 0.98 & -0.32 & -0.3265 & & 2005 & \\
\hline 10 & 38,45 & -377.195 & 0.75 & -0.32 & -0.4266 & -0.136 & 881 & 861 \\
\hline 10 & 38.15 & -377.195 & 0.73 & -0.32 & $-0,1383$ & & 860 & \\
\hline 10 & 36.45 & -377.195 & 0.72 & -0.37 & -0.4444 & & 849 & \\
\hline \multicolumn{8}{|c|}{ Rata rata } & 926 \\
\hline
\end{tabular}

Data untuk kondisi Rebound

\begin{tabular}{|c|c|c|c|c|c|c|c|}
\hline \multicolumn{8}{|c|}{ UII KONSTANTA RFDAMAN (VISCOUS+FAICTION) } \\
\hline $\begin{array}{c}\text { Massa } \\
\langle k|\end{array}$ & $\begin{array}{c}\text { Beral } \\
\text { (N) }\end{array}$ & $\begin{array}{l}\text { WAKTU } \\
\text { (s) }\end{array}$ & $\begin{array}{l}\text { STROKE } \\
\text { (iii) }\end{array}$ & $\begin{array}{l}\text { KECEPATAN } \\
(\mathrm{m} / \mathrm{s})\end{array}$ & $\begin{array}{l}\text { v rata2 } \\
(\mathrm{m} / \mathrm{s})\end{array}$ & $\begin{array}{c}c \\
c \\
\left(\mathrm{~N}_{2} / \mathrm{m}\right)\end{array}$ & $\begin{array}{l}\text { Crata2 } \\
(\mathrm{Ns} / \mathrm{m})\end{array}$ \\
\hline 0 & 0 & 0 & 0 & 0 & 0 & 0 & 0 \\
\hline 25 & 245.250 & 0.91 & 0.32 & 0.35163 & 0.35556 & 697 & טים \\
\hline 25 & 245.250 & 0.89 & 0.32 & 0.35955 & & 682 & \\
\hline 25 & 245.250 & 0.9 & 0.32 & 0.35556 & & 690 & \\
\hline 30 & 294.300 & 0.67 & 0.32 & 0.47761 & 0.50073 & 616 & 589 \\
\hline 30 & 294.300 & 0.61 & 0.32 & 0.52459 & & 561 & \\
\hline 30 & 294.300 & 0.64 & 0.32 & 0.50000 & & 589 & \\
\hline 35 & 343.350 & 0.6 & 0.32 & 0.53333 & 0.55922 & 644 & 615 \\
\hline 35 & 343.350 & 0.54 & 0.32 & 0.59259 & & 579 & \\
\hline 35 & 313.350 & 0.58 & 0.32 & 0.55172 & & 622 & \\
\hline \multicolumn{7}{|c|}{ Rata-rate } & 631 \\
\hline
\end{tabular}

Dari tabel diatas dapat diperoleh nilai friction damping dengan cara hasil pengujian (VISCOUS+FRICTION) dikurangi nilai viscous damping yang sudah diperoleh sebelumnya

Nilai akhir inilah yang disebut dengan nilai final friction damping. Lebih detailnya dapat dilihat pada tabel berikut:

\begin{tabular}{|c|c|c|c|}
\hline Kompanen HEMSA & Crebound (N.s'm) & Cempression (N.s/n) & $\mathrm{Cd}(\mathrm{N} s \mathrm{~m})$ \\
\hline Viscoust Friction damping & $63 \mathrm{I}$ & 926 & 778.5 \\
\hline Viscous danowing & 518 & 694 & 606 \\
\hline \multicolumn{3}{|c|}{ Niki Final Fricticn demuxing } & 172.5 \\
\hline
\end{tabular}

\subsection{Penentuan Nilai Electric Dumping}

Pada kondisi ini nilai electric damping sudah dalam keadaan terpasang beban lampu 30 watt. Berikut data pengujian dari electric damping:

Konstanta Redaman Electric damping (Compression):

\begin{tabular}{|c|c|c|c|c|c|c|c|c|}
\hline \multicolumn{9}{|c|}{ UII XONSIANIA IIIIAMMAN IUIAI + BI BAR IAMIPU 30 WAII } \\
\hline $\begin{array}{c}\text { Mussu } \\
(\mathrm{kg})\end{array}$ & $\begin{array}{l}\text { Massa } \\
\text { I hoider } \\
\text { (N) }\end{array}$ & Berat $(\mathrm{N})$ & $\begin{array}{c}\text { WAKTU } \\
\text { (5) }\end{array}$ & $\begin{array}{c}\text { STROKE } \\
(\mathrm{m})\end{array}$ & $\underset{[m / s]}{v}$ & $\begin{array}{l}\text { viulat } \\
(\mathrm{m} / \mathrm{s})\end{array}$ & $\begin{array}{c}c \\
(\mathrm{~N}: / \mathrm{m})\end{array}$ & $\begin{array}{l}\mathrm{Cl} \text { Clutu2 } \\
\langle\mathrm{Ns} / \mathrm{m}\rangle\end{array}$ \\
\hline 0 & 0 & 0 & 0 & 0 & 0 & 0 & 0 & 0 \\
\hline 0 & 28.43 & -279.095 & 1.46 & -0.32 & -0.21918 & -0.220 & 1273 & 1270 \\
\hline a & 38.5 & 279.095 & 1.47 & $0.3)$ & 0.22535 & & 1238 & \\
\hline 0 & 28.45 & -279.095 & 1.49 & -0.32 & -0.21477 & & 1300 & \\
\hline 5 & 33.45 & -328.145 & 1.32 & -0.32 & -0.24242 & -0.247 & 1354 & 1330 \\
\hline 5 & 3.25 & 328.145 & 1.29 & 0.37 & 0.24806 & & 1323 & \\
\hline 5 & 33.45 & -328.145 & 1.28 & $-0,32$ & -0.25000 & & 1313 & \\
\hline 10 & 38.45 & -377.195 & 1.1 & -0.32 & -0.29091 & -0.280 & 1297 & 1348 \\
\hline 10 & $38<5$ & 377.195 & 1.15 & 0.37 & 0.27826 & & 1356 & \\
\hline 10 & 38.15 & -377.195 & 1.18 & -0.32 & -0.27119 & & 1391 & \\
\hline \multicolumn{8}{|c|}{ Rata-rata } & 1316 \\
\hline
\end{tabular}

Konstanta Redaman Electric damping (Rebound)

\begin{tabular}{|c|c|c|c|c|c|c|c|}
\hline \multicolumn{8}{|c|}{ UII KUNSI ANIA KEDAMAN IOIAL + BEZAN LAMPU 20 WAII } \\
\hline $\begin{array}{c}\text { Massa } \\
(\mathrm{kg})\end{array}$ & $\begin{array}{l}\text { Berat } \\
\text { (N) }\end{array}$ & $\begin{array}{c}\text { WnikTu } \\
\text { (s) }\end{array}$ & $\begin{array}{c}\text { STROKE } \\
\text { (m) }\end{array}$ & $\begin{array}{c}v \\
(m / s)\end{array}$ & $\begin{array}{c}\text { v rata2 } \\
(\mathrm{m} / \mathrm{s})\end{array}$ & $\begin{array}{c}c \\
(\mathrm{Ns} / \mathrm{m})\end{array}$ & $\begin{array}{l}\text { C rata2 } \\
\left(\mathrm{N}_{5} / \mathrm{m}\right)\end{array}$ \\
\hline 0 & 0 & 0 & 0 & 0 & 0 & 0 & 0 \\
\hline 30 & 294.300 & 1.29 & 0.32 & 0.24806 & 0.25133 & 1186 & $11 / 1$ \\
\hline 30 & 294.300 & 1.27 & 0.32 & 0.25197 & & 1168 & \\
\hline 30 & 291.300 & 1.26 & 0.32 & 0.25397 & & 1159 & \\
\hline 35 & 313.350 & 1.09 & 0.32 & 0.29358 & 0.29818 & 1170 & 1152 \\
\hline 35 & 343,350 & 1.07 & 0.32 & 0.29907 & & 1148 & \\
\hline 35 & 343.350 & 1.06 & 0.32 & 0.30189 & & 1137 & \\
\hline 40 & 392400 & 0.83 & 0.32 & 0.38554 & 0.39362 & 1018 & 997 \\
\hline 40 & 392.400 & 0.82 & 0.32 & 0.39024 & & 1006 & \\
\hline 40 & 392.400 & 0.79 & 0.32 & 0.40506 & & 969 & \\
\hline & & & tata-rata & & & & 1107 \\
\hline
\end{tabular}

Dari tabel diatas dapat diperoleh nilai electric damping dengan cara hasil pengujian (Uji Konstanta Redaman Total + Beban Lampu 30 Watt) dikurangi nilai (Viscous + Friction damping) yang sudah diperoleh sebelumnya. Nilai akhir inilah yang disebut dengan nilai final friction damping. Lebih detailnya dapat dilihat pada tabel berikut:

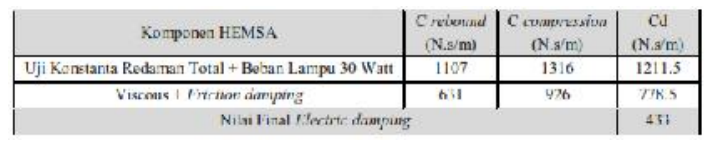


4.4 Total distribusi redaman

Untuk melihat distribusi nilai redaman (Viscous, Friction dan Electric damping) dapat dilihat pada tabel berikut:

\begin{tabular}{|c|c|c|c|}
\hline $\begin{array}{c}\text { Komponen } \\
\text { HEMSA }\end{array}$ & \multicolumn{4}{|c|}{$\begin{array}{c}\text { Rebound } \\
\text { (N.s/m) }\end{array}$} & $\begin{array}{l}\text { Compre } \\
\mathrm{s}\end{array}$ & $\begin{array}{c}\text { Cd } \\
\text { (N.s/m) }\end{array}$ \\
\hline $\begin{array}{c}\text { Viscous } \\
\text { damping }\end{array}$ & 518 & 694 & 606 \\
\hline $\begin{array}{c}\text { Friction } \\
\text { damping }\end{array}$ & 113 & 232 & 172.5 \\
\hline $\begin{array}{c}\text { Electric } \\
\text { damping }\end{array}$ & 476 & 390 & 433 \\
\hline $\begin{array}{c}\text { Total } \\
\text { damping coef }\end{array}$ & 1107 & 1316 & 1211.5 \\
\hline \multicolumn{1}{|c|}{ Kondisi Uji } \\
\hline $\begin{array}{c}\text { Komponen } \\
\text { HEMSA }\end{array}$ & $\begin{array}{c}\text { Rebound } \\
\text { (N.s/m) }\end{array}$ & $\begin{array}{c}\text { Compres } \\
(\mathrm{N} . \mathrm{s} / \mathrm{m})\end{array}$ & $\begin{array}{c}\text { Cd } \\
(\mathrm{N} . \mathrm{s} / \mathrm{m})\end{array}$ \\
\hline $\begin{array}{c}\text { Viscous } \\
\text { damping }\end{array}$ & 518 & 694 & 606 \\
\hline $\begin{array}{c}\text { Friction } \\
\text { damping }\end{array}$ & 113 & 232 & 172.5 \\
\hline $\begin{array}{c}\text { Electric } \\
\text { damping }\end{array}$ & 476 & 390 & 433 \\
\hline $\begin{array}{c}\text { Total } \\
\text { damping } \\
\text { coefficient }\end{array}$ & 1107 & 1316 & 1211.5 \\
\hline
\end{tabular}

\section{KESIMPULAN}

Dari hasil pengujian diperoleh nilai viscous dumping sebesar 518 N.s/m (rebound) dan 694 N.s/m (Compression), friction dumping sebesar 113 N.s/m (rebound) dan 232 N.s $/ \mathrm{m}$ (Compression), electic dumping sebesar 476 N.s/m (rebound) dan 390 N.s/m (Compression). Sektor Viscous dumping memiliki rerata dumping koefisien tertinggi sebesar $606 \mathrm{~N} . \mathrm{s} / \mathrm{m}$ dan terendah pada friction dumping sebesar 172.5 N.s $/ \mathrm{m}$. Besaran dumping koefisien masing-masing item dijadikan data acuan dalam pengembangan RSA kedepan.

\section{DAFTAR PUSTAKA}

[1] Anderson, Peter."Global Energy Consumption Due to Friction in Passenger Cars". VTT Technical Research Centre of Finland, Finland. (2011).
[2] Li Chuan, dkk."Integration of shock absorption and energy harvesting using a hydraulic rectifier".University of Ottawa, Canada. (2013)

[3] Samantaray,A.K."Analysis of preloaded liquid spring/damper shock absorbers". Indian Institute of Technology, India. (2007)

[4] Kwon, Chen."Vehicle Tube Hydraulic Shock Absorber". Zheijiang University, China. (2011).

[5] Sobendan Estia research."Modeling of An Electromechanical Energy Harvesting System Integrated In Car Dampers" ,France. (2011)

[6] Bou, Liu. "Vibratory Energy-Recycling Hydraulic Damping System”.JiuJiang University, China. (2010).

[7] Putranto, Adityo. "Studi Eksperimen Karakteristik Getaran dan Energi Bangkitan hydraulic electro mechanic shock absorber double port Dengan Rasio Cylinder 40:30 Akibat Variasi Pembebanan Listrik. Tugas Akhir", Tugas Akhir, Institut Teknologi Sepuluh Nopember, Surabaya. (2014).

[8] Ardiansyah Putra, Ilham. "Studi Eksperimen Karakteristik Getaran Dan Energi Listrik Bangkitan Dari Hidraulik-Mekanik-Elektro Magnetic Shock Absorber Akibat Variasi Pembebanan", Tesis, Institut Teknologi Sepuluh Nopember, Surabaya. .(2014).

[9] Choifin, Muhammad."Studi Eksperimen Karakteristik Getaran Dan Energi Listrik Bangkitan Dari Hidraulik-Mekanik-Elektro Magnetic Shock Absorber Akibat Variasi Pembebanan Listrik”. Tesis. Institut Teknologi Sepuluh Nopember, Surabaya. (2014).

[10] Tri Handrianto ,Dodi ."Studi Eksperimen Karakteristik Gaya Redaman dan Energi Bangkitan Hydraulic Electro Mechanic Shock Absorber DuaSelang compression Satu Rebound Dengan Pembebanan Akumulator", Tugas Akhir, Institut Teknologi Sepuluh Nopember, Surabaya. (2014).

\section{Biodata Penulis}

Wanda Afnison, S.Pd, M.T, Dosen Jurusan Teknik Otomotif Fakultas Teknik Universitas Negeri Padang

Drs. Bahrul Amin, S.T., M.Pd., Dosen Jurusan Teknik Otomotif Fakultas Teknik Universitas Negeri Padang 
